\title{
Efficient isolation of keratin from protein-rich waste biomass: A practical approach to minimize environmental impact and valorize waste biomass
}

\section{Tapan Kumar Maity}

Central Salt and Marine Chemicals Research Institute CSIR

\section{Nripat Singh}

Central Salt and Marine Chemicals Research Institute CSIR

\section{Pradip Vaghela}

Central Salt and Marine Chemicals Research Institute CSIR

\section{Arup Ghosh}

Central Salt and Marine Chemicals Research Institute CSIR

\section{Sanju Singh}

Central Salt and Marine Chemicals Research Institute CSIR

\section{Pramod B Shinde}

Central Salt and Marine Chemicals Research Institute CSIR

\section{Rosy Alphons Sequeira}

Central Salt and Marine Chemicals Research Institute CSIR

Kamalesh Prasad ( $\nabla$ drkamaleshp@gmail.com)

Central Salt and Marine Chemicals Research Institute CSIR https://orcid.org/0000-0003-2366-1664

\section{Research}

Keywords: waste biomass, quaternary ammonium base, dissolution, keratin, plant health, environmental impact

Posted Date: January 31st, 2022

DOI: https://doi.org/10.21203/rs.3.rs-889945/v2

License: (c) (i) This work is licensed under a Creative Commons Attribution 4.0 International License. Read Full License 


\section{Abstract}

Among protein-containing biomass wastes, waste animal wool, poultry feather, and human hair are considered as one of the most important renewable sources of keratin. Although waste animal wool (WAW) and human hair (WHH) are used for the production of the number of products but the substantial quantity of short fibers not suitable for spinning and being unusable is thrown as waste resulting considerable environmental problems in terms of their accumulation in water bodies resulting water clogging and other related problems. Similarly, poultry waste especially the waste chicken feathers (WCF) is dumped or burnt, or used as low-value fertilizer in certain applications. To extract more value-added products such as keratin from such wastes, herein suitability of an aqueous solution of quaternary ammonium hydroxide known as tetramethylammonium hydroxide (25\% w/w TMAOH in water) to solubilize these protein wastes and to extract keratin from them was investigated. The solvent could solubilized $c a$. $39-44 \%$ w/w of WAW, $19-25 \%$ of WHH, and $55-60 \%$ of WCF. Crude keratin with ca 19-20\%, $35-37 \%$, and $69-74 \%$ were isolated from WAW, WHH, and WCF respectively. The chemical and structural stability of keratin thus isolated was established. The recovered TMAOH, insoluble WAW, and WCF were found to be nontoxic to soil microbes. The recovered $\mathrm{TMAOH}$ thus generated after isolation of keratin was used for green gram (Vigna radiata) seed treatment and a substantial increase in the height (4-12\%) and weight (9-58\%) of the plants were observed. Treating biomass waste as a source of high-value compounds may minimize environmental impact by reducing the waste load.

\section{Introduction}

Due to the increasing demand using bio-based raw materials for various applications in material chemistry and engineering, the demand for resourcing such materials is receiving renewed attention from various researchers. To meet the economics and sustainability of any material prepared, the low-cost sourcing of the starting material is of utmost importance. Keratin is one of such proteins, which is the most abundant protein and the major component of hair, feathers, nails, and horns of mammals, reptiles, birds and it can be easily extracted from the biomass [1, 2]. Its biodegradability, bio-compatibility, high polarity, high chemical reactivity, and affinity to adhere to cells make it attractive for various applications [3]. The application areas for keratin are in tissue engineering, in the treatment of certain water pollutants, in various biomedical applications, textile industries, etc. [4-8]. The number of functional materials has been designed using keratin as a base in various formats such as films, fibers, coating, and composite membranes [9-12]. As mentioned above keratin is widely available but its extraction from the biomass is not a very easy process due to the difficulty in cleaving a-helix and $\beta$-sheet of the protein due to the strong hydrogen bonding and disulfide bonding between polypeptide chains [13]. Although several traditional methods such as reduction, re-oxidation, acid-alkali, enzymatic, and sulfitolysis are being used to extract and solubilize keratin from various biomass resources [14-17] but toxicity associated with several of the solvents and chemicals pose environmental as well as health concerns [13]. One of the improved methods of extraction of keratin so far reported uses L-cysteine as a reducing agent to extract wool keratin [18]. 
To bring sustainability in agriculture practices, various reforms in terms of use of better seed quality, deployment of improved technologies towards harvesting and sowing of seeds, etc., being deployed to increase productivity to cater to the food need of the ever-increasing population of the world [19-21]. Seed treatment is considered to be one of the most crucial operations in agriculture which ensures increased crop yield, quality, and productivity. As because the infested seed can lead to unhealthy plants which may affect productivity and hence healthy seed for plants is of utmost importance for sustainable agriculture. New research methods are implemented to improve seed quality integrating combinations of seed technologies like seed coatings, priming, dressing, pelleting, etc. [22]. However, the increasing trend of using pesticides for seed treatment has created an alarming situation in terms of the presence of pesticide residues in seeds and further transportation of the harmful molecules to the fruits and flowers affecting human health. Hence alternative seed treatment solutions are often sought and researched in this area.

Quaternary ammonium electrolytes (QAEs) are emerging as a very good solvent system for the dissolution of biopolymers such as cellulose and certain agricultural wastes [23, 24]. They are believed to resolve the complications such as high viscosity, multiple operations, and the use of high temperature being faced in the dissolution of cellulose [25]. Among the QAEs it was observed that the anions play a very crucial role in the dissolution process. The poor interaction of the biopolymers (having nonaccessible hydroxyl groups due to intra hydrogen bonding) with the QAEs having anions such as chloride and bromide has encouraged to use of the QAEs having hydroxyl group as anion for the effective and efficient dissolution processes [25]. In one of the attempts, we have solubilized waste human hair in $40 \%$ aqueous solution of tetra-butyl ammonium hydroxide (TBAOH) and isolated keratin and melanin [26].

Herein we have demonstrated the suitability of a quaternary ammonium base namely tetramethylammonium hydroxide ( $25 \% \mathrm{w} / \mathrm{w}$ TMAOH in water) for the dissolution of waste animal wool, waste human hair, and waste chicken feather and isolation of keratin from the solutions. We have further demonstrated the suitability of the waste recovered solvent for seed treatment. In the previous study, we have considered $40 \%$ aqueous solution of $\mathrm{TBAOH}$ as an ionic liquid but considering the fact that upon evaporation of water present in it, it was not possible to get a molten salt, herein we are calling the solution as a quaternary ammonium base solution rather than ionic liquid. Further, TBAOH was found to be a bit toxic to the soil microbes upon long-term investigation and hence we have now used TMAOH which is found to be nontoxic to the soil microbes for seed treatment.

\section{Experimental}

\subsection{Material}

Tetramethylammonium hydroxide $\left[\mathrm{N}\left(\mathrm{CH}_{3}\right)_{4}{ }^{+} \mathrm{OH}^{-}\right]\left(25 \% \mathrm{w} / \mathrm{w}\right.$ in $\left.\mathrm{H}_{2} \mathrm{O}\right)$ was purchased from Molychem, Mumbai, India. Synthetic melanin and Standard wool keratin were purchased from Sigma Aldrich and TCl respectively. The soil sample was collected from the institute garden $\left(21.7590^{\circ} \mathrm{N}, 72.1443^{\circ} \mathrm{E}\right)$ and sludge was collected from a waste of a food processing industry situated in Bhavnagar city $\left(21.7515^{\circ} \mathrm{N}\right.$, 
$\left.72.0971^{\circ} \mathrm{E}\right)$. The samples were randomly collected and stored in air-tight containers. All the solvents such as acetone, $\mathrm{HCl}$, hexane, and dichloromethane, etc. used were of AR grade and were used as received from commercial suppliers.

The domestic Indian sheep wool used in these experiments was collected from Bhavnagar's local area, Gujarat, India. At first, the sheep wool was washed three times with water for removing the dust particles. It was cleaned and defatted using a 1:1 v/v mixture of hexane and dichloromethane in a soxhlet extractor for $48 \mathrm{~h}$. The cleaned wool sample was dried in a vacuum oven at $70^{\circ} \mathrm{C}$ for $48 \mathrm{~h}$.

Waste human hair was collected from a haircutting salon situated in Bhavnagar City. As collected waste human hair samples $(50 \mathrm{~g})$ were washed and rinsed thoroughly with $70 \%(\mathrm{v} / \mathrm{v})$ ethanol and distilled water. Washed hair samples were then soaked in the mixture of chloroform and methanol $(2: 1 \mathrm{v} / \mathrm{v})$ for 24 $\mathrm{h}$ for de-lipidization and air-dried.

The waste chicken feathers were collected from local poultry farms situated in Bhavnagar city. As collected feathers were boiled $\left(70^{\circ} \mathrm{C}\right)$ with enough amount of water to wash the material for $3 \mathrm{~h}$ changing the water every after one hour and air-dried. Dry feathers were treated with petroleum ether (40-60) [1:20] for $24 \mathrm{~h}$ to remove feather lipid. The delipidized feathers were powdered and were used as a starting material.

\subsection{Dissolution of WAW, WHH, and WCF in aqueous tetramethylammonium hydroxide (TMAOH): The} wool fibers (10 to $400 \mathrm{mg}$ ) were added gradually into a vial containing $1.0 \mathrm{~mL}$ of aqueous solution TMAOH as shown in Table 1 at $65^{\circ} \mathrm{C}$ (optimized temperature) for $6 \mathrm{~h}$ (Optimized time duration) under an atmosphere of nitrogen gas with continuous stirring in glass vials until the fibers were visibly solubilized. In addition, a laser beam was used to identify the presence of small particles, through the observation of any light scattering from the solutions. In some cases, particularly at high wool contents, the rate of wool dissolution appeared to decrease markedly probably due to the increased viscosity of the solution. Hence, we describe these ultimate observations as "limiting solubility" to indicate that these are kinetically limited values rather than thermodynamic solubilities. After $6 \mathrm{~h}$, partial dissolution of wool fibers was observed in $\mathrm{TMAOH}$ ( $25 \% \mathrm{w} / \mathrm{w}$ in water) and the presence of the insoluble part of fibers was confirmed by observing the aliquots under an optical light microscope (100X). The insoluble part was separated using a centrifuge (8000 rpm for 10 minutes). The addition of acetic acid and acetone mixture (1:4) in the solution resulted in the precipitation of light yellowish color crude wool keratin shown in Scheme 1. The keratin was isolated by centrifugation and washed with acetone $(x)$ to remove solvent residues and placed in a desiccator under reduced pressure to obtain dried keratin powder. Keratin thus obtained was sealed and stored at $4{ }^{\circ} \mathrm{C}$ before use. The water and acetone mixture (3-5 times) remained after the isolation of keratin were evaporated to obtain a viscous solution ( $r-\mathrm{TMAOH})$.

The de-lipidized hair fibers $(\mathrm{WHH})(10$ to $200 \mathrm{mg}$ ) were added progressively into the vial containing $1 \mathrm{~mL}$ of TMAOH (25 wt\% in water) at room temperature under the atmosphere of nitrogen gas with continuous stirring (1-9 h). After $9 \mathrm{~h}$, complete dissolution of WHH was observed and the absence of the insoluble 
WHH fibers was confirmed by observing the aliquots under an optical light microscope $(100 \mathrm{X})$. Black coloured crude melanin was obtained after $\mathrm{HCl}$ treatment which was isolated followed by the addition of acetic acid and acetone mixture (1:4) into the solution which resulted formation of pale brown coloured precipitates (crude keratin). The keratin was isolated by centrifugation and washed with acetone (3-5 times) and placed in desiccators under reduced pressure to obtain dried crude keratin powder.

The delipidized chicken feather (10 to $600 \mathrm{mg}$ ) were added gradually into a vial containing $1.0 \mathrm{~mL}$ of $\mathrm{TMAOH}$ ( $25 \mathrm{wt} \%$ in water) at room temperature for $6 \mathrm{~h}$ (optimized time duration) under an atmosphere of nitrogen gas with continuous stirring (magnetic stirrer) in glass vials until the fiber was observed visually to complete dissolved. In addition, a laser beam was used to identify the presence of small particles, through the observation of any light scattering from the solutions. In some cases, particularly at high feather contents, the rate of feather dissolution appeared to decrease markedly, probably due to the increased viscosity of the solution. After $6 \mathrm{~h}$ partial dissolution of chicken feather fibers was observed and the presence of the insoluble part of fibers was confirmed by observing the aliquots under an optical light microscope (100X). The insoluble part was separated using a centrifuge at $9000 \mathrm{rpm}$ for 10 minutes. The addition of acetic acid and acetone mixture (1:4) in the solution resulted in the precipitation of light white colour crude feather keratin. The keratin was isolated by centrifugation and washed with acetone (3-5 times) to remove the solvent and placed in a desiccator under reduced pressure to obtain dried keratin powder.

Water present in the waste TMAOH recovered after isolation of keratin (r-TMAOH) in all the above dissolution processes was used for seed treatment (green gram).

2.3. Cup experiment of green gram: Green gram seeds of the variety P9072 (Karnal) harvests were obtained from the Indian Agricultural Research Institute, Delhi. To perform the germination experiments, seeds were washed thoroughly with $2 \%$ sodium hypo chloride solution and sterile Milli q water ( $x 2$ ). A factorial completely randomized design was used in the present study. The experiment consisted of treating this variety of green gram soaked for 11 minutes in the solutions (r-TMAOH). Briefly, each seed was soaked in $10 \mathrm{~mL}$ of different $\mathrm{r}-\mathrm{TMAOH}$ solutions in sterilized test tubes that were ventilated with cotton plugs and then sowed in a cup. The growth of the plant was monitored for 30 days in 4 days of interval. Water was used for soaking the seeds and was termed a controlled experiment.

2.4. Total microbial count measurement: Microbial growth was monitored in $T M A O H\left(25 \% \mathrm{w} / \mathrm{w}\right.$ in $\left.\mathrm{H}_{2} \mathrm{O}\right)$, the residue obtained after the dissolution of wool (r-wool), and recovered TMAOH after the isolation of keratin (r-TMAOH) to ascertain the microbial toxicity and thus the soil compatibility of the samples. The microbes used were isolated from a soil sample collected from the garden area of the institute and an industrial sludge sample collected from Bhavnagar city. In a typical experiment, $500 \mu \mathrm{L}$ samples were added and plated with agar media. The sludge was diluted to $10^{-1}$ and $1 \mathrm{gm}$ soil in $10 \mathrm{~mL}$ PBS buffer (pH 7) and diluted to $10^{-2}$. $100 \mu \mathrm{L}$ from dilution was spread on TSA plates (duplicates) and incubated at 30 ${ }^{\circ} \mathrm{C}$ for 5 days and development of total microbial colony in CFU was monitored after 5 days. 
2.5 Characterization: Powder X-ray diffraction (PXRD) patterns were obtained at $25^{\circ} \mathrm{C}$ using a Philips $X^{\prime}$ pert MPD System. For each XRD experiment, Cu Ka1 radiation $(\lambda=1.540 \AA)$ was produced at $40 \mathrm{kV}$ and $30 \mathrm{~mA}$. The data were collected in Brag-Brentano $(\theta / 2 \theta)$ horizontal geometry using a $2 \theta$-range of $5^{\circ}$ to $80.0^{\circ}$ with a step size of $0.02^{\circ}$ and an accompanying scan speed of $0.1^{\circ} \mathrm{s}^{-1}$. Infrared spectroscopy (FTIR) was performed using a Perkin Elmer, G-FTIR spectrometer (Spectrum GX, GSA). The CHNS analyzer (Elementar, Vario Micro Cube) was used for elemental analyses. ${ }^{13} \mathrm{C}$ NMR spectra were recorded at $400 \mathrm{MHz}$ on a Bruker Avance-400 spectrometer. The ${ }^{13} \mathrm{C}$ CP MAS NMR spectra of these samples were acquired using a $4 \mathrm{~mm}$ rotor with a Kel-fcap at a $10 \mathrm{kHz}$ spinning rate. The contact time in the CP MAS experiments was $2.4 \mathrm{~ms}$ with a recycle delay of $1 \mathrm{~s}$ and $\mathrm{cw}$ decoupling. The number of scans was $\sim 90$ 000 to 100000 . The microscopic image of complete dissolution was monitored using a light microscope with 100X magnification (Fine Vision Microscope, India).

\section{Results \& Discussion}

Suitability of aqueous tetramethylammonium hydroxide $(\mathrm{TMAOH}, 25 \% \mathrm{w} / \mathrm{w}$ in water) to solubilize waste biomass such as animal wool, human hair and chicken feather and isolation of keratin is investigated. Earlier we have reported solubility of waste human hair in tetrabutylammonium hydroxide (TBAOH, $25 \%$ $\mathrm{W} / \mathrm{w}$ in water) and isolated keratin and melanin [26]. Further, we have hypothesized the use of recovered $\mathrm{TBAOH}$ as nitrogen fortifier for nitrogen-deficient organic fertilizers but upon investigation, it was observed that TBAOH inhibits the growth of soil microbes while TMAOH does not (Supporting information, Figure S1). Hence herein we have considered studying the suitability of the latter for waste biomass treatment with an aim to use the recovered solvent for seed treatment. It can be observed from Table 1, ca. $39-44 \%$ of animal wool waste (WAW), $19-25 \%$ of waste human hair (WHH), and $55-60 \%$ waste chicken feather (WCF) is soluble in the quaternary ammonium base solution. It was further noted that the solubility of WHH and WCF was achieved at room temperature while the solubility of WAW was achieved at $65^{\circ} \mathrm{C}$. Solubility was confirmed by observing the aliquots of the solutions under an optical microscope (100 X) as described earlier (Supporting information Figures S2, S3, and S4) [26]. The maximum crude keratin could be isolated from WCF with a yield of $c a$. $69-74 \%$ followed by WHH and WAW. Further from Scheme 1, it can be observed that a substantial amount of insoluble mass during the dissolution of WAW (ca. 55-60\%) and WCF (ca. 40-45\%) was generated. The lower yield of keratin from WAW is perhaps due to the high-temperature operation which is known to degrade proteins. Furthermore, crude melanin with yield (ca. 20-25\%) as identified by UV-Vis spectrophotometer (Supporting Figure S5) could be isolated from human hair. The structure of melanin was confirmed by CP-MAS (Supporting Information Figure S6) [26]. The insoluble mass obtained from WAW and WCF was further investigated to find their suitability for agriculture applications. In all the cases, the TMAOH utilized was recovered (ca. 30-40\%) and was further investigated for soil microbe suitability and seed treatment. 
Table 1

Optimization of the process for the dissolution of waste biomass in TMAOH (25\% w/w solution in water).

\begin{tabular}{|c|c|c|c|c|c|}
\hline $\begin{array}{l}\text { Sl. } \\
\text { No }\end{array}$ & $\begin{array}{l}\text { Waste } \\
\text { Biomass }\end{array}$ & $\begin{array}{l}\text { Temp. } \\
\left({ }^{\circ} \mathrm{C}\right)\end{array}$ & $\begin{array}{l}\text { Total solubility (g/100 } \\
\mathrm{mL})\end{array}$ & $\begin{array}{l}\text { Crude } \\
\text { Keratin } \\
(\% \mathrm{w} / w) *\end{array}$ & $\begin{array}{l}\text { Time duration/ Remark } \\
\text { (h) }\end{array}$ \\
\hline 1 & Animal wool & $\begin{array}{l}65.0 \pm \\
2.0\end{array}$ & $41.75 \pm 2.36$ & $\begin{array}{l}19.75 \pm \\
0.96\end{array}$ & $6.0 \pm 0.50$ \\
\hline 2 & Human Hair & $\mathrm{RT}^{\#}$ & $22.50 \pm 2.88$ & $\begin{array}{l}35.75 \pm \\
1.50\end{array}$ & $8.5 \pm 0.50$ \\
\hline 3 & $\begin{array}{l}\text { Chicken } \\
\text { Feather }\end{array}$ & $\mathrm{RT}^{\#}$ & $58.00 \pm 2.44$ & $\begin{array}{l}72.00 \pm \\
2.44\end{array}$ & $6.5 \pm 0.50$ \\
\hline
\end{tabular}

It is necessary to investigate the chemical and structural stability of proteins after dissolution in any solvent to ensure the preservation of the crucial functional behavior of the protein. The FT-IR measurements were done to investigate the change in functional moieties of the protein after dissolution by comparing the spectra with standard wool keratin. The comparison of the spectral bands as shown in Figure 1 (a-d) showed characteristic bands due to the peptide bonds (-CONH) and ensure chemical and structural stability of proteins present. It can be seen from the FT-IR spectra of standard natural wool keratin and keratin isolated from all the three waste biomass exhibit identical broad absorption bands of characteristic keratinous fibers between $3350 \mathrm{~cm}^{-1}-3050 \mathrm{~cm}^{-1}$ corresponding to the $\mathrm{N}-\mathrm{H}$ and $\mathrm{O}-\mathrm{H}$ stretching vibration of proteins. The amide $\mathrm{I}$ band, which is ascribed to $\mathrm{C}=\mathrm{O}$ stretching vibration, occurs in the range of $1700 \mathrm{~cm}^{-1}$ to $1600 \mathrm{~cm}^{-1}$ [27]. An absorption band at $1515 \mathrm{~cm}^{-1}$ was observed due to $\mathrm{C}-\mathrm{N}$ stretching and $\mathrm{N}-\mathrm{H}$ bending vibrations (Amide II). The $\mathrm{C}=\mathrm{O}$ stretching and $\mathrm{N}-\mathrm{H}$ bending vibrations of Amide-I and amide-II corresponds to $a$-helix and $\beta$-sheet of the keratin. In this Figure, no band is observed in the range of $2550-2600 \mathrm{~cm}^{-1}$ indicating an absence of S-H vibration due to cysteine. The low intensity of the vibration bands at $1083 \mathrm{~cm}^{-1}, 1128 \mathrm{~cm}^{-1}$, and $1161 \mathrm{~cm}^{-1}$ (S-O asymmetric stretching) further confirm the absence of cysteine. In addition to this, the other bands at $1645 \mathrm{~cm}^{-1}, 1402 \mathrm{~cm}^{-1}$, and 1274 $\mathrm{cm}^{-1}$ correspond to the primary amide, secondary amide, and tertiary amide respectively. Furthermore, the vibration band observed at $1300-1000 \mathrm{~cm}^{-1}$ is due to the disulfide bonds formed between two alphahelixes of keratin. The characteristic bands are identical to the one observed for the standard wool keratin indicating preservation of the structural integrity of the protein during extraction in $\mathrm{TMAOH}$.

Since crystallinity of proteins is very crucial for its functional behavior and often gets disrupted by the external environment. The crystallinity pattern of the natural wool keratin and keratin isolated from all the three waste biomass using an aqueous solution of TMAOH was invested by powdered XRD as shown in Figure 2 (a-d). 
The standard natural wool keratin showed broad diffraction (20) peak at ca. $8.65^{\circ}$ and $19.96^{\circ}$, corresponding to the a-helix and $\beta$-sheet structures of the protein (Figure 2a) [28]. Similar diffraction patterns corresponding to the $a$-helix and $\beta$-sheet structure of keratin were observed for all the keratin samples extracted from the three waste biomass samples [Figure $2(b-d)$ ]. However, both the peaks are significantly intense in extracted keratin samples from WAW and WCF suggesting a higher content of the $\beta$-sheet structure in the samples.

${ }^{13} \mathrm{C}$ CP-MAS spectra of the standard natural wool keratin and keratin isolated from all the three waste biomass using aqueous TMAOH are shown in Figure 3 (a-d). The spectra showed an asymmetric peak at ca.173 ppm due to the amide carbonyl carbons of the keratin protein. The peak at $129.9 \mathrm{ppm}$ is related to the aromatic group-containing amino acids in the keratin. The chemical shifts of a-carbons are recorded between 52 and 56 ppm, while chemical shifts due to the $\beta$-carbons in leucine residues and cross-linked cysteine residues are observed at $40.1 \mathrm{ppm}$. The carbon peak recorded at $17.5 \mathrm{ppm}$ can be assigned to alanine and the peak at $22.4 \mathrm{ppm}$ of keratin is due to the $\beta$-carbons of leucine. The intense peak centered at $25.0 \mathrm{ppm}$ can be ascribed to the presence of $\beta$-carbons in glutamic acid, glutamine residues, arginine, and cysteine. The signals at lower chemical shifts are due to the alkyl groups of the side chains [10]. The a-carbon peak between 52 - 56 ppm is broadened in the isolated crude keratin from WAW and WHH which may be due to the ability of the L-cysteine to disrupt the hydrogen bonding in keratin leading to the unfolding of the polypeptide chains [10]. This would result in the formation of a greater fraction of $\beta$ sheet structures which is in agreement with the XRD data discussed above.

As discussed above, a substantial amount of insoluble mass or residue was generated during dissolution, and to utilize them for further applications they were subjected to elemental analysis, and the residue obtained from WAW dissolution was found to have $3.18 \pm 0.12 \% \mathrm{~N}$ and $27.35 \pm 0.29 \%$ organic carbon, while residue obtained from WCF dissolution was found to have $8.46 \pm 0.19 \% \mathrm{~N}$ and $28.49 \pm 0.20 \%$ organic carbon. Due to the presence of nitrogen and carbon, they may be treated as good soil nutrients and hence their soil microbial toxicity was investigated. As shown in Figures S7 and S8, soil and sludge microbes grow in both the residue samples and the TMAOH solution indicating their suitability for placing in the soil. It was noted that the pure TMAOH was also nontoxic to the microbes evident from the formation $n$ of microbial colonies of both soil and sludge in the media consisting of the solution (Figure 4A and B). Moreover, as shown in Figures 4C and 4D, 32 Nos of the microbial colony for the soil bacteria were developed in the media consisted of r-TMAOH, while the CFU count was 31 for the sludge bacteria (Figure 4D).

As shown in Scheme 1, about 30-40\% of the processed TMAOH could be recycled (r-TMAOH). As mentioned above, seed treatment needs some good benign chemicals to enhance the plant quality after germination without affecting human health. Hence use of r-TMAOH for seed treatment is proposed herein. To find the suitability of the recovered solvents for seed treatment, each of the green gram seeds was soaked in $10 \mathrm{~mL}$ r-TMAOH/water (1:1) for 11 minutes and sowed in well-conditioned soil samples under a controlled environment. As it can be seen in Figures S9 and S10 (Supporting information), the plant height was increased in comparison to control treatment (water) by $4 \%$, and weight was increased 
by $58 \%$ for the r-TMAOH treatment obtained from WAW processing after 30 days of sowing, while for $\mathrm{r}$ TMAOH obtained from WCF processing, the plant height and plant weight were significantly increased by $12 \%$ and $29 \%$ respectively after an identical day of sowing. Moreover, after similar days of sowing for $r-$ TMAOH treatment obtained from WHH processing, plant height and plant weight significantly increased by $9 \%$. A representative image showing the increase in height of green gram plants by $\mathrm{r}-\mathrm{TMAOH}$ treatment obtained from WAW, WCF, and WHH processing is depicted in Figure 5.

\section{Conclusion}

Herein we have demonstrated a new approach for the complete utilization of protein-rich waste biomass such as waste animal wool, human hair, and poultry feathers. The waste biomass was initially solubilized in an aqueous solution of tetramethylammonium hydroxide followed by isolation of keratin. It was observed that ca. $39-44 \% \mathrm{w} / \mathrm{w}$ of waste animal wool, $19-25 \%$ of waste human hair, and $55-60 \%$ of a waste chicken feather could be solubilized in the solvent. The nitrogen and carbon rich insoluble mass obtained from the dissolution of animal wool and chicken feather was found to be soil-compatible. Crude keratin with ca $19-20 \%, 35-37 \%$, and $69-74 \%$ were isolated from waste animal wool, human hair, and chicken feather respectively. The preservation of the chemical and structural stability of keratin indicated the stability of the protein structure in the solvent system. Normally high temperature is employed to extract protein from waste biomass but herein keratin could be isolated from waste chicken feathers and human hair at room temperature. However, an elevated temperature was required in the case of waste animal wool. The recovered solvent obtained after the isolation of keratin was found to be compatible with soil and sludge microbes and hence was used for green gram (Vigna radiata) seed treatment. A substantial increase in the height (4-12\%) and weight (9-58\%) of the plants were observed after the treatment. Considering the easier isolation of protein and maximum utilization of the chemicals, the process demonstrated may be considered as a sustainable method for the production of keratin.

\section{Declarations}

\section{Availability of data and materials}

The raw data is available by contacting the authors.

Competing interests : Authors have no problem in submitting the above manuscript to Sustainable Environment Research (SER) for consideration for publication as a full paper. We don't have any

Conflict of interest.

Funding : The funder of the projects is acknowledged in the manuscript and it is council of scientific and Industrial Research, New Delhi India, UGC and DST India.

\section{Authors' contributions :}


Tapan Kumar Maity : Carried out the experimental work and characterization

Nripat Singh: Assisted in the experimental work and chattarerization

Pradip Vaghela: Plant growth and germination studies

Arup Ghosh : Conceptualised Plant growth and germination studies

Sanju Singh : Soil compatibility stuidirs

Pramod B. Shinde : Conceptualized Soil compatibility studies

Rosy Alphons Sequeira : Litertaure Survey

Kamalesh Prasad : Over all conceptualization of the work, drafting and writing of manuscript, communication, coordination etc

Acknowledgements : KP, AG, and PV acknowledge CSIR, New Delhi for financial support for this research (MLP0027). TKM thanks CSIR for a project fellowship and NS thanks to UGC for Senior Research Fellowship. RAS acknowledges DST, India for Inspire Fellowship. PBS and SS acknowledge the Department of Science \& Technology for financial support. The Analytical and Environmental Science Division and Centralized Instrument Facility of the Institute is acknowledged for providing instrumentation facilities.

\section{References}

1. Aluigi A, Corbellini A, Rombaldoni F, Mazzuchetti G. Wool-derived keratin nanofiber membranes for dynamic adsorption of heavy-metal ions from aqueous solutions. Text Res J 2013;83:1574-86. https://doi.org/10.1177/0040517512467060.

2. Zhang H, Liu J. Electrospun poly(lactic-co-glycolic acid)/wool keratin fibrous composite scaffolds potential for bone tissue engineering applications. J Bioact Compat Polym 2013;28:141-53. https://doi.org/10.1177/0883911512472565.

3. Isarankura Na Ayutthaya S, Tanpichai S, Sangkhun W, Wootthikanokkhan J. Effect of clay content on morphology and processability of electrospun keratin/poly(lactic acid) nanofiber. Int J Biol Macromol 2016;85:585-95. https://doi.org/10.1016/j.ijbiomac.2016.01.041.

4. A. Aluigi, A. Varesano, A. Montarsolo, C. Vineis, F. Ferrero, G. Mazzuchetti CT. Electrospinning of keratin/poly(ethylene oxide)blend nanofibers. J Appl Polym Sci 2007;104:863-870. https://doi.org/10.1002/app.25623.

5. Zoccola M, Aluigi A, Patrucco A, Vineis C, Forlini F, Locatelli P, et al. Microwave-assisted chemical-free hydrolysis of wool keratin. Text Res J 2012;82:2006-18. https://doi.org/10.1177/0040517512452948. 
6. Rouse JG, Dyke ME Van. A Review of Keratin-Based Biomaterials for Biomedical Applications 2010:999-1014. https://doi.org/10.3390/ma3020999.

7. Silva R, Fabry B, Boccaccini AR. Fibrous protein-based hydrogels for cell encapsulation. Biomaterials 2014;35:6727-38. https://doi.org/10.1016/j.biomaterials.2014.04.078.

8. Dickerson MB, Sierra AA, Bedford NM, Lyon WJ, Gruner WE, Mirau PA, et al. Keratin-based antimicrobial textiles, films, and nanofibers. J Mater Chem B 2013;1:5505-14. https://doi.org/10.1039/c3tb20896f.

9. Gazioglu Ruzgar D, Altun Kurtoglu S, Bhullar SK. A Study on Extraction and Characterization of Keratin Films and Nanofibers from Waste Wool Fiber. J Nat Fibers 2020;17:427-36. https://doi.org/10.1080/15440478.2018.1500335.

10. Zhao Z, Song C, Zhou J, Hu R, Xiao H, Liu Y, et al. An eco-friendly method based on the self-glue effect of keratins for preparing Fe304-coated wool. J Appl Polym Sci 2020;137:1-11. https://doi.org/10.1002/app.49179.

11. Zhang H, Ma H, Zhang R, Wang K, Liu J. Construction and characterization of antibacterial PLGA/wool keratin/ornidazole composite membranes for periodontal guided tissue regeneration. J Biomater Appl 2020;34:1267-81. https://doi.org/10.1177/0885328220901396.

12. Zhong X, Li R, Wang Z, Wang W, Yu D. Eco-fabrication of antibacterial nanofibrous membrane with high moisture permeability from wasted wool fabrics. Waste Manag 2020;102:404-11. https://doi.org/10.1016/j.wasman.2019.11.005.

13. Zheng S, Nie Y, Zhang S, Zhang X, Wang L. Highly Efficient Dissolution of Wool Keratin by Dimethylphosphate lonic Liquids. ACS Sustain Chem Eng 2015;3:2925-32. https://doi.org/10.1021/acssuschemeng.5b00895.

14. Yu XJ, Tian JY, Wang JB. Reduction dissolution and cross-linking of wool keratin. Wool Text J 2012;40:46-9.

15. Vasconcelos A, Freddi G, Cavaco-Paulo A. Biodegradable materials based on silk fibroin and keratin. Biomacromolecules 2008;9:1299-305. https://doi.org/10.1021/bm7012789.

16. Mi X, Li W, Xu H, Mu B, Chang Y, Yang Y. Transferring feather wastes to ductile keratin filaments towards a sustainable poultry industry. Waste Manag 2020;115:65-73. https://doi.org/10.1016/j.wasman.2020.07.022.

17. Navone L, Moffitt K, Hansen KA, Blinco J, Payne A, Speight R. Closing the textile loop: Enzymatic fibre separation and recycling of wool/polyester fabric blends. Waste Manag 2020;102:149-60. https://doi.org/10.1016/j.wasman.2019.10.026.

18. Wang K, Li R, Ma JH, Jian YK, Che JN. Extracting keratin from wool by using I-cysteine. Green Chem 2016;18:476-81. https://doi.org/10.1039/c5gc01254f.

19. Pannell DJ. Uncertainty and Adoption of Sustainable Farming Systems. Risk Manag Environ Agric Perspect 2003:67-81. https://doi.org/10.1007/978-94-017-2915-4_5.

20. Guilherme MR, Aouada FA, Fajardo AR, Martins AF, Paulino AT, Davi MFT, et al. Superabsorbent hydrogels based on polysaccharides for application in agriculture as soil conditioner and nutrient 
carrier: A review. Eur Polym J 2015;72:365-85. https://doi.org/10.1016/j.eurpolymj.2015.04.017.

21. Scott NR, Chen H, Cui H. Nanotechnology Applications and Implications of Agrochemicals toward Sustainable Agriculture and Food Systems. J Agric Food Chem 2018;66:6451-6. https://doi.org/10.1021/acs.jafc.8b00964.

22. Hakeem KR. Role of Seed Quality in Improving Crop Yields. In Crop Production and Global Environmental Issues. 2015.

23. Zhong C, Wang C, Huang F, Jia H, Wei P. Wheat straw cellulose dissolution and isolation by tetra-nbutylammonium hydroxide. Carbohydr Polym 2013;94:38-45. https://doi.org/10.1016/j.carbpol.2013.01.043.

24. Zhong C, Wang C, Wang F, Jia H, Wei P, Zhao Y. Application of tetra-n-methylammonium hydroxide on cellulose dissolution and isolation from sugarcane bagasse. Carbohydr Polym 2015;136:979-87. https://doi.org/10.1016/j.carbpol.2015.10.001.

25. Kostag M, Jedvert K, Achtel C, Heinze T, El Seoud OA. Recent advances in solvents for the dissolution, shaping and derivatization of cellulose: Quaternary ammonium electrolytes and their solutions in water and molecular solvents. Molecules 2018;23. https://doi.org/10.3390/molecules23030511.

26. Singh N, Prasad K. Multi-tasking hydrated ionic liquids as sustainable media for the processing of waste human hair: A biorefinery approach. Green Chem 2019;21:3328-33. https://doi.org/10.1039/c9gc00542k.

27. Kakkar P, Madhan B, Shanmugam G. Extraction and characterization of keratin from bovine hoof: A potential material for biomedical applications. J Korean Phys Soc 2014;3:1-9. https://doi.org/10.1186/2193-1801-3-596.

28. Liu X, Nie Y, Meng X, Zhang Z, Zhang X, Zhang S. DBN-based ionic liquids with high capability for the dissolution of wool keratin. RSC Adv 2017;7:1981-8. https://doi.org/10.1039/c6ra26057h.

\section{Schemes}

Scheme 1 is in the supplementary files section.

\section{Figures}




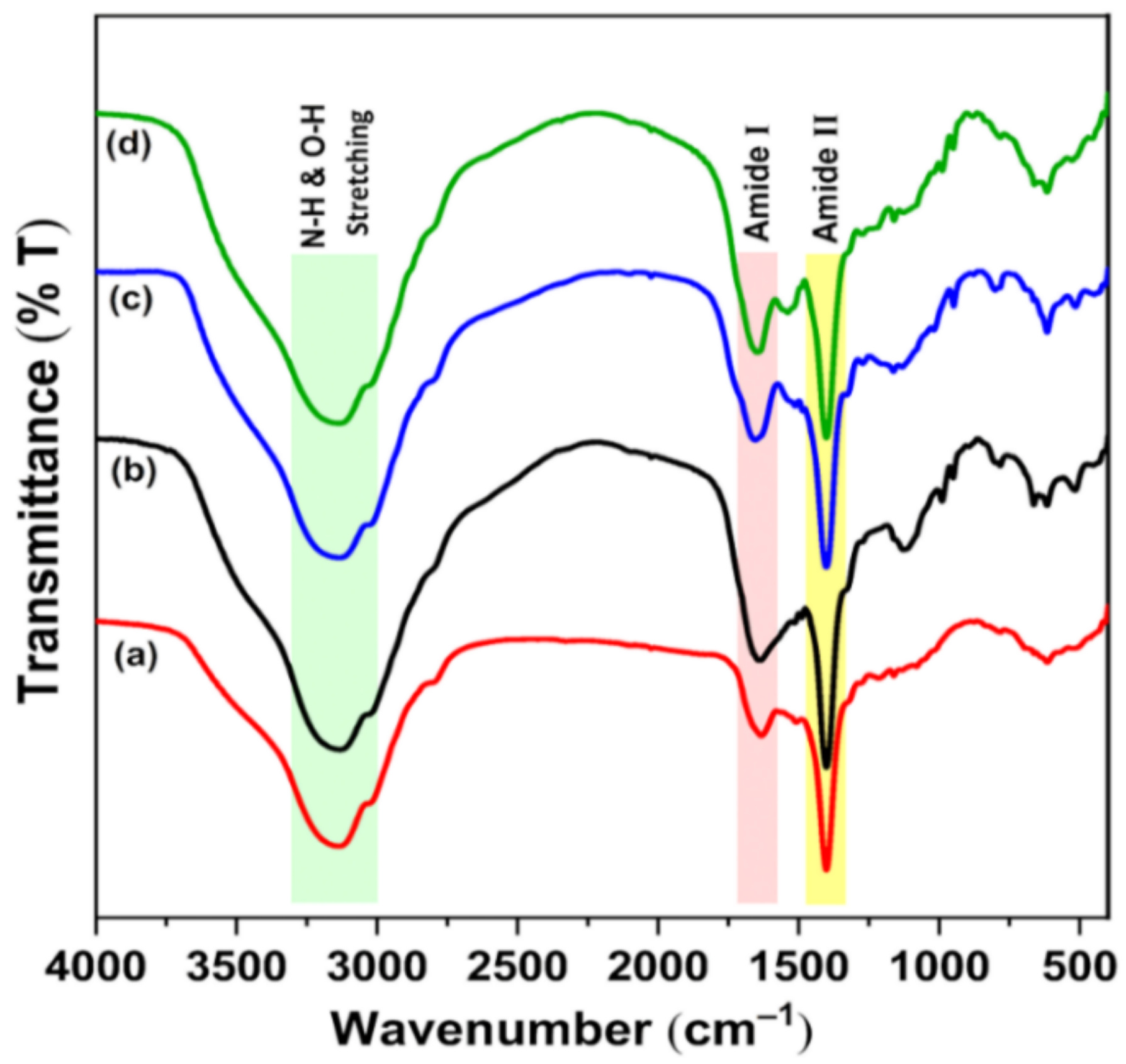

Figure 1

FT-IR spectra of (a) standard wool keratin and keratin isolated from waste (b) animal wool (c) human hair (d) chicken feather. 


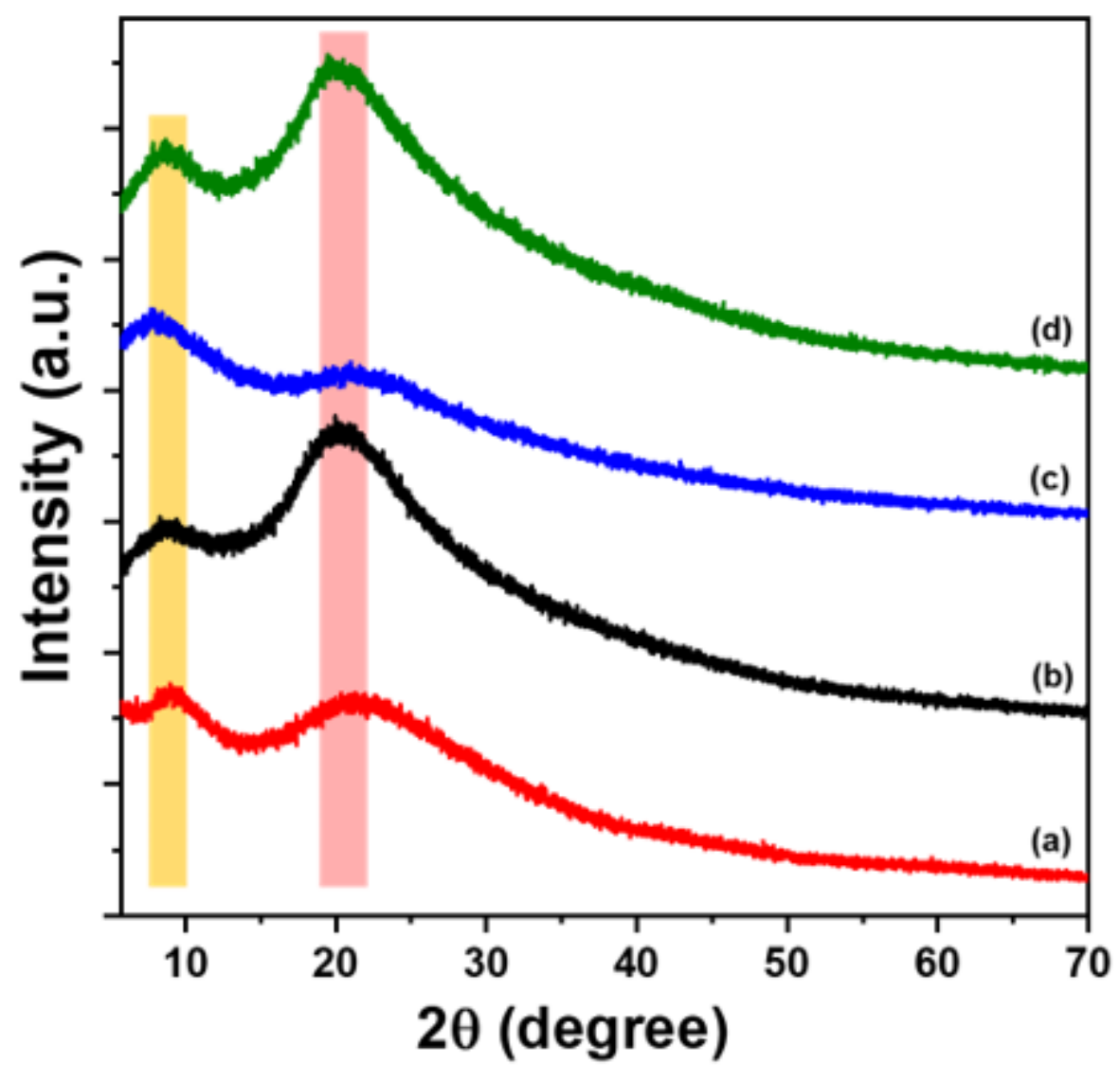

Figure 2

XRD spectra of (a) standard wool keratin and keratin isolated from waste (b) animal wool (c) human hair (d) chicken feather. 


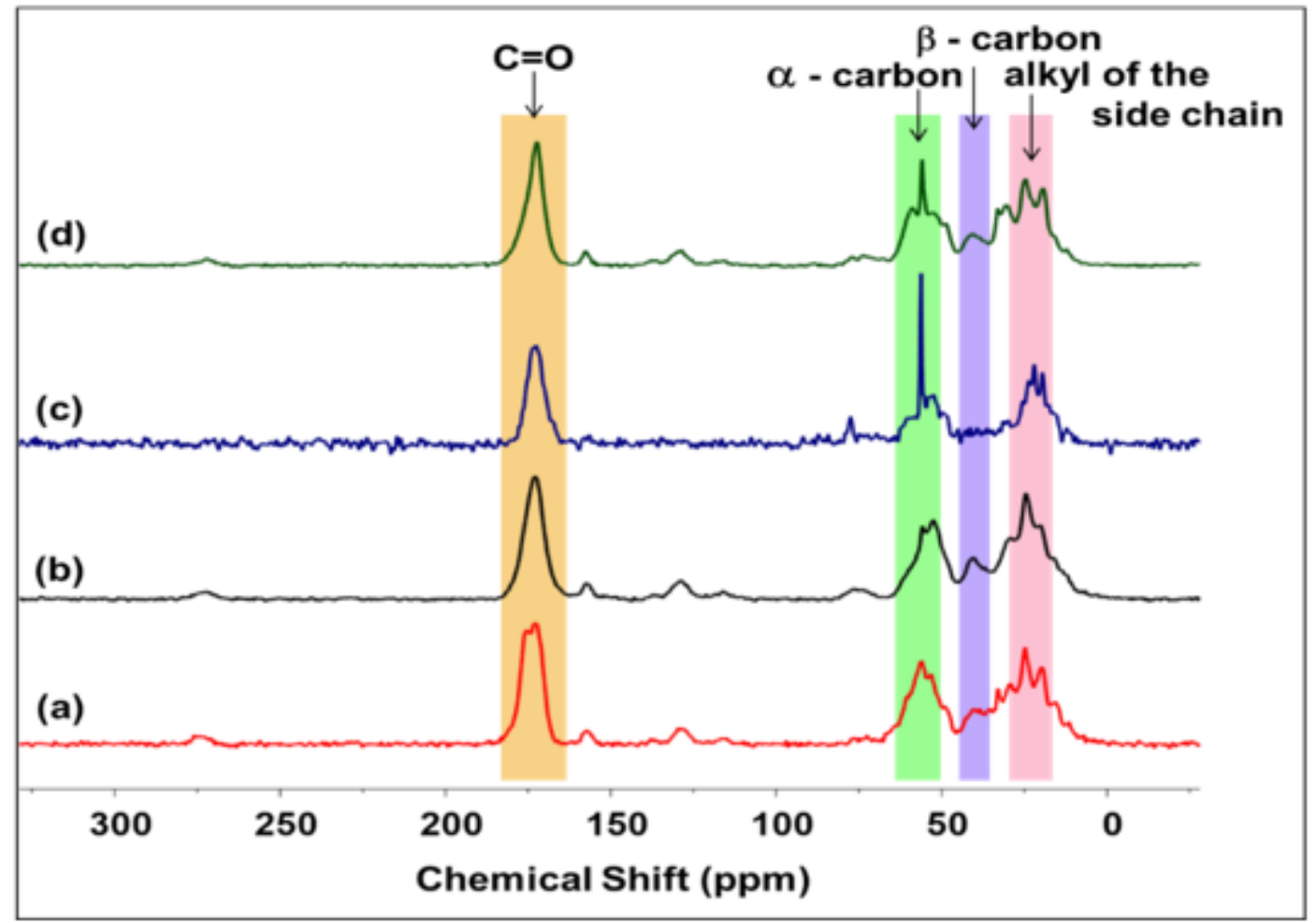

\section{Figure 3}

The ${ }^{13} \mathrm{C}$ CP MAS NMR spectra of keratin isolated from waste (b) animal wool (c) human hair (d) chicken feather and comparison with (a) standard wool keratin.
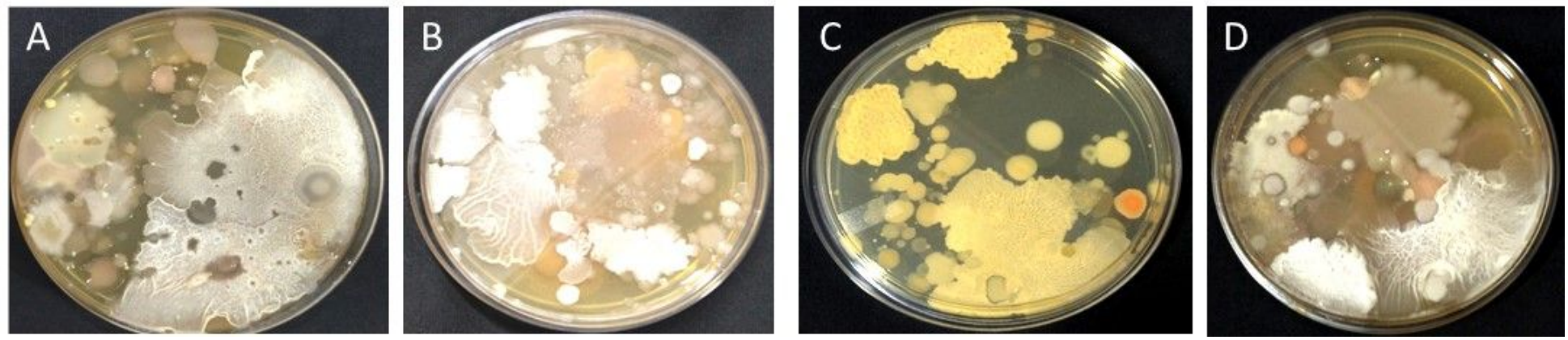

Figure 4

Microbial growth in the sample for microbial colonies isolated from soil (A) Pure TMAOH (25\% in water), (C) Recycled TMAOH and microbial colonies isolated from industrial sludge (C) Pure TMAOH (25\% in water), and (d) Recovered TMAOH. 


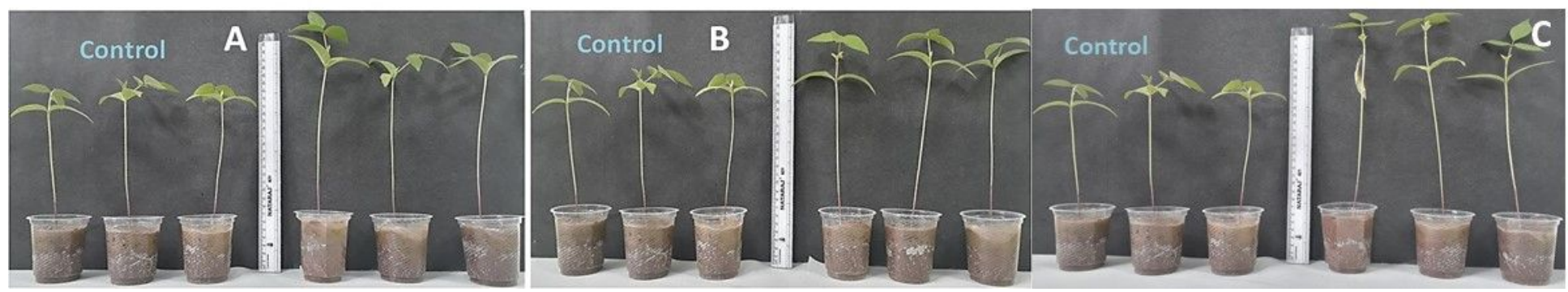

\section{Figure 5}

(A) Effect of application of recovered TMAOH (obtained from animal wool, chicken feather, and human hair processing) and water mixture (1:1) for seed treatment on shoot length of green gram after 15 days of sowing.

\section{Supplementary Files}

This is a list of supplementary files associated with this preprint. Click to download.

- Supportinginformation.docx

- floatimage1.jpeg 